\title{
El juez de ejecución de penas y las medidas de seguridad en Colombia: un análisis crítico sobre sus orígenes, consagración normativa y funciones ${ }^{*}$
}

\author{
The judge for the enforcement of penalties and security measures in Colombia: \\ A critical analysis of its origins, the normative consecration, and functions
}

\author{
Luz Mireya Mendieta Pineda* \\ Mayda Goyte Pierre ${ }^{* * *}$ \\ Islen Yahir Oviedo ${ }^{* * * *}$
}

Fecha de recepción: 5 de agosto del 2019

Fecha de aprobación: 5 de diciembre del 2019

\begin{abstract}
Artículo de investigación, producto del proyecto de investigación "Sistema alternativo penal", ya terminado del grupo de investigación Derechos Humanos y Medio Ambiente, de la Universidad Pedagógica y Tecnológica de Colombia, en colaboración con el grupo de investigación Escuela de Derecho Penal Nullum Crimen Sine Lege UN, reconocido y clasificado en categoría A por Colciencias, 2017, de la Universidad Nacional de Colombia y la Universidad de La Habana, Cuba.

Citar como Mendieta Pineda, L. M., Goyte Pierre, M. y Oviedo I. Y. (2020). El juez de ejecución de penas y las medidas de seguridad en Colombia: un análisis crítico sobre sus orígenes, consagración normativa y funciones. Via Inveniendi et Iudicandi, 15(1), 91-118. Dor: https://doi.org/10.15332/19090528/5743

* $\quad$ Profesora asociada de la Facultad de Derecho y Ciencias Sociales de la Universidad Pedagógica y Tecnológica de Colombia. Abogada de la Universidad Libre. Especialista en Instituciones Jurídico Penales de la Universidad Nacional de Colombia. Magíster en Derecho Procesal de la Universidad Libre (Colombia) y doctora de la misma Universidad. E-mail: luz.mendieta@uptc.edu.co orcid: 0000-0003-0371-5012

*** Doctora en Derecho Penal de la Universidad de La Habana (Cuba), profesora titular de Derecho Penal y actual vicerrectora de La Universidad de La Habana (Cuba). E-mail: mayda@lex.uh.cu ORCID: 0000-0002-8525-5074

**** Profesor de la Universidad El Bosque (Colombia), Universidad Nacional de Colombia y profesor de posgrados en Derecho Penal de la Universidad La Gran Colombia. Abogado de la Universidad Nacional de Colombia y magíster en Derecho de la misma universidad. Estudiante de doctorado en Derecho de la Universidad Nacional de Colombia. Miembro del grupo de investigación Red de Política Criminal Sistémica "Extrema Ratio" UN, reconocido y clasificado A1 por Minciencias en el 2018, de la Universidad Nacional de Colombia. E-mail: iyoviedo@unal.edu.co orciD: 0000-0002-4902-8149
\end{abstract}




\title{
RESUMEN
}

Este artículo tiene como objetivo examinar de manera crítica la figura del juez de ejecución de penas y medidas de seguridad en Colombia desde su origen, naturaleza jurídica, deberes, funciones y competencia. Busca también recordar las leyes y acuerdos del Consejo Superior de la Judicatura que hicieron posible el surgimiento y puesta en marcha de este funcionario. La metodología de investigación es documental y pretende, a través de la consulta doctrinaria, jurisprudencial, de normatividad y de acuerdos e informes del Inpec, recoger datos sobre el tema que sustentan la investigación para un análisis de aproximación al objeto de estudio y concluir sobre su eficacia frente a sus funciones. Entre los hallazgos, se destaca la importancia de este funcionario en la ejecución de la pena como el encargado de velar por el cumplimiento de las sentencias condenatorias; sin embargo, con respecto a la función inspectora que tiene como juez constitucional en la fase de ejecución de la pena, esto en la realidad resulta letra muerta porque, como lo seńalada la jurisprudencia, hay una constante violación de los derechos humanos para el privado de la libertad.

Palabras clave: juez de ejecución penas, Estado social de derecho, legislador, funciones, jurisprudencia.

\begin{abstract}
The purpose of this article is to critically examine the figure of the judge for the enforcement of penalties and security measures in Colombia from its origin, legal nature, duties, functions, and competence. This papers also recalls the laws and agreements of the Superior Council of Judicature that made possible the emergence and implementation of this specific category of official. The methodology for this examination is based on a documentary research developed through doctrinal and jurisprudential consultation, regulations, agreements, and reports of the National Penitentiary and Prisons Institute (Inpec) to collect data supporting the research for an approach analysis of the object of study so as to conclude on its effectiveness according to its functions. Among the findings, the importance of this official in the execution of guilty verdicts as the person in charge of ensuring compliance with convictions is pointed out. Nevertheless,
\end{abstract}


according to the inspection function that this kind of constitutional judge has through the executing phase of the verdict, the role has become meaningless due to the persistent violation of the prisoner's human rights, according to what the jurisprudence has stated.

Keywords: enforcement of penalties judge, social State of law, legislator, functions, jurisprudence. 


\section{INTRODUCCIÓN}

A partir del concepto de derechos humanos y de su protección en la Constitución Nacional, especialmente el artículo primero, que configura a Colombia como un Estado social de derecho y que, por lo tanto, reconoce los derechos fundamentales de las personas, se despliega un esfuerzo estudioso por visibilizar la figura del juez de ejecución de penas y medidas de seguridad y sus funciones, de acuerdo con lo establecido en la ley y en la jurisprudencia (Garzón, 2013)

La figura de los jueces de ejecución de penas y medidas de seguridad (en adelante JEPYMS), es relativamente nueva, por lo menos en Colombia. Su funcionamiento se reporta desde 1994, en cumplimiento del Acuerdo 14 del 7 de junio de 1993, expedido por el Consejo Superior de la Judicatura, pese a que la figura fue consagrada en las leyes 2700 de 1991 y 65 de 1993.

La competencia del juez radica en la vigilancia y cumplimiento de la pena impuesta al sentenciado y de la medida de seguridad asignada al inimputable, de acuerdo con lo consagrado en el Código Penal, el Código de Procedimiento Penal y el Código Penitenciario y Carcelario. Como puede apreciarse, estos jueces cumplen un papel importante en el campo penitenciario, debido a la seriedad y control que, a través de ellos, se le impone a la ejecución penal.

La competencia del juez comienza con la ejecutoria de la sentencia condenatoria para el imputable y termina con su cumplimiento o con su archivo por alguna de las causas de extinción de la pena establecidas en el artículo 88 del Código Penal ${ }^{1}$. No se visibiliza, en esta oportunidad, la medida aplicable al inimputable, ya que ella será objeto de estudio en otro artículo que ya es objeto de investigación.

El presente artículo busca indagar sobre la figura del JEPYMS, su origen y sus funciones, con el fin de analizar algunos problemas que favorecen que la función inspectora no se cumpla de acuerdo con lo consagrado en la Ley 1709 del 2014.

1 La muerte del condenado, el indulto, la amnistía impropia, la prescripción, la rehabilitación para las sanciones privativas de derechos cuando operen como accesorias, la exención de punibilidad en los casos previstos en la ley y las demás que seńale la ley. 
Luz Mireya Mendieta Pineda, Mayda Goyte Pierre, Islen Yahír Oviedo

El primer apartado aborda el origen de la figura del JEPYMs en el derecho comparado. El segundo analiza la implementación de los juzgados de ejecución de penas y medidas de seguridad en Colombia. El tercero se ocupa de la competencia de estos jueces y de la fase de ejecución y expone las tensiones entre las funciones y el trabajo de esos jueces en clave analítica y crítica, teniendo como perspectiva la propuesta teórica de la escuela de la política criminal sistémica (Huertas, 2019) para colegir hoy algunas implicaciones en la labor real del juez en comento.

\section{Metodología}

La metodología de investigación es documental y pretende, a través de la consulta doctrinaria, jurisprudencial y normativa (acuerdos e informes del Inpec, adicionalmente) recoger datos sobre el JEPYMs para desarrollar un análisis crítico de aproximación al objeto de estudio. Se logra así construir un proceso de aprehensión y trasmisión del conocimiento con el fin de concluir sobre su eficacia frente a sus funciones, especialmente, la inspectora (Tirado, Bedoya y Blanco, 2016).

\section{ORIGEN DEL JUEZ DE EJECUCIÓN DE PENAS Y MEDIDAS DE SEGURIDAD EN EL DERECHO COMPARADO}

La aparición de la figura del JEPYMs es reciente. En el derecho comparado, apenas se comenzó a conocer en el siglo XxI con el nombre de juez de vigilancia penitenciaria o juez de control de ejecución de la pena. El primer país de Suramérica donde comenzó a regularse fue en Brasil, con la expedición de la Ley federal de 1922. Luego se retomó en el Código de Procedimiento Penal de 1940. Al ser una figura innovadora, se acogió en Europa, específicamente en Italia en 1930, con el nombre de juez de vigilancia penitenciaria, con dos clases de facultades: una decisoria y otra consultiva.

Italia fue el primer país que organizó la participación de los magistrados en la ejecución de las sanciones penales. De allí trascendió a Portugal, con la Ley del 16 de mayo de 1944 y los decretos del 27 y 30 de abril de 1945. Después surge en Francia mediante el artículo 721 del Código de Procedimiento Penal de 1958, reiterado por 
las leyes del 17 de julio de 1970, del 29 de septiembre de 1972 y del 11 de julio de 1975, con dos funciones específicas: como encargado de las resoluciones que tienen que ver con la aplicación de las penas privativas de la libertad y como responsable de controlar la aplicación de los beneficios de la condena de ejecución condicional, la libertad condicional y la asistencia y tutela de los penados liberados.

Luego, en Portugal, se recoge esta figura en el Decreto ley 783 de 1976, con algunas modificaciones estipuladas por el Decreto ley 222 del 30 de mayo de 1977 y el 204 del 24 de julio de 1978, que reglamentaron los tribunales de ejecución de penas (De Escamilla, 1986, p. 75-88). Al aprobarse las Reglas Mínimas para el Tratamiento de Reclusos del comité de Ministros Europeos de 1973, se recomendó la creación de un órgano judicial que se encargara de la vigilancia de la ejecución penal.

Wexler y Calderón (2003), en un estudio sobre la figura del juez de vigilancia penitenciario en España, lo toman como propuesta para impulsar un modelo jurídico que estableciera juzgados de reinserción en los sistemas angloamericanos. Mientras tanto, Subijana (2005) comparte que la creación de estos funcionarios obedeció a la necesidad de concretar los preceptos constitucionales. Agrega que es un órgano judicial, en el orden jurisdiccional penal, a quien se le atribuye el control de la ejecución de la pena de prisión.

\section{Origen en Colombia}

Debe aclararse la definición de juez de ejecución de penas y medidas de seguridad a partir de la presente investigación: el juez de ejecución ${ }^{2}$ de penas (Huertas, 2019) ${ }^{3}$ y medidas de seguridad ${ }^{4}$ en Colombia es el juez competente del cumplimiento de las penas impuestas en sentencia condenatoria al imputable y de las medidas de seguridad impuestas al inimputable que ha proferido el juez penal municipal o del

2 Acción y efecto de ejecutar, pasar del proyecto a la ejecución (Larousse, 2002, p. 380).

3 Gracia, Boldova, y Alastuey seńalan que "la pena es la privación o restricción de bienes jurídicos impuestos conforme a la ley, por los órganos jurisdiccionales competentes, al culpable de una infracción penal” (Gracia, Boldova, y Alastuey, 2012, p. 21).

4 Las medidas de seguridad corresponden a la privación o restricción del derecho constitucional fundamental a la libertad, impuesta judicialmente por el Estado, con fines de curación, tutela y rehabilitación a persona declarada previamente como inimputable (Posada, 2010, p. 360). 
Luz Mireya Mendieta Pineda, Mayda Goyte Pierre, Islen Yahír Oviedo

El juez de ejecución de penas y las medidas de seguridad en Colombia...

circuito, el juez especializado o los magistrados de la sala penal de los tribunales o de la sala de decisión penal de la Corte Suprema de Justicia. La competencia se asume una vez haya quedado ejecutoriado el fallo o la medida de seguridad y sus actuaciones comienzan a surtirse sobre el cuaderno de copias que ha enviado el despacho que profirió la sentencia o la medida de seguridad. Así mismo, la competencia termina cuando se decreta la liberación ${ }^{5}$, la extinción de la pena ${ }^{6}$ y, de modo concomitante, el archivo definitivo del proceso. Finalmente, el JEPYMs es el encargado de garantizar los derechos fundamentales de la población condenada y de velar por ellos.

En Colombia, la figura del JEPyms tiene su origen en la Constitución de 1991. Así lo ratifico la Corte Constitucional cuando promulgó su Sentencia T 065 de 1995: "Los jueces de ejecución de penas y medidas de seguridad se incluyen dentro del término ‘jueces' establecido en el artículo 86 de la Carta Política”. Se trata de una figura que recogió el Código de Procedimiento Penal de esa época, en sus artículos $75^{[7]}$ y $76^{[8]}$ de la Ley 2700 de 1991 que establece su competencia. Dos años después de que entró en vigencia la mencionada ley, se expide el actual Código Penitenciario y Carcelario (Ley 65 de 1993), que retoma los lineamientos expuestos en la ley procedimental, regula la figura de este juez y complementa su competencia en el artículo 51, que, hasta la fecha, ha sido modificado en dos oportunidades, la última de las cuales es la Ley 1709 del 2014.

5 El artículo 67 de la Ley 599 del 2000 expone así la figura: "extinción y liberación. Transcurrido el período de prueba sin que el condenado haya incurrido en las conductas de que trata el artículo anterior, la condena queda extinguida y la liberación se tendrá como definitiva, previa resolución judicial que así lo determine.”

6 El artículo 88 de la Ley 599 del 2000 establece las causales que la originan: la muerte del condenado, el indulto, la amnistía impropia, la prescripción, la rehabilitación para las sanciones privativas de derecho cuando aparecen como accesorias, la exención de punibilidad en los casos previstos en la ley y las demás que esta seńale.

7 Los JEPYMs, en ejercicio de su facultad de ejecución de las sentencias proferidas por los jueces penales, conocen: (1) de todo lo relacionado con la libertad del condenado que deba otorgarse con posterioridad a la sentencia, rebaja de penas, redención de pena por trabajo, estudio o enseńanza, y extinción de la condena; (2) de la verificación del lugar y condiciones en que se deba cumplir la pena o la medida de seguridad; (3) de la acumulación jurídica de penas en caso de varias sentencias condenatorias proferidas en procesos distintos contra la misma persona; (4) de la aplicación del principio de favorabilidad cuando debido a una ley posterior hubiere lugar a reducción o extinción de la pena; (5) del reconocimiento de la ineficacia de la sentencia condenatoria cuando la norma incriminadora haya sido declarada inexequible o haya perdido su vigencia.

8 Las apelaciones interpuestas contra las decisiones proferidas por los jueces de ejecución de penas y medidas de seguridad serán resueltas por los superiores jerárquicos de los jueces que hayan dictado las sentencias condenatorias de primera instancia. 


\section{IMPLEMENTACIÓN DE LOS JUZGADOS DE EJECUCIÓN DE PENAS Y MEDIDAS DE SEGURIDAD EN COLOMBIA}

Ante la necesidad de que comenzaran a operar los juzgados de ejecución de penas y medidas de seguridad y con el fin de darle cumplimiento a las leyes 2700 de 1991 y 65 de 1993, (Sánchez Montoya, 2018), el Consejo Superior de la Judicatura expide una serie de acuerdos en pro de incentivar en cada uno de los tribunales superiores el funcionamiento de estos despachos, a través del nombramiento de los respectivos jueces. De esta manera, se expide el Acuerdo 14 del 7 de junio de 1993, que, al invocar las facultades conferidas por el numeral 5 del artículo 4. ${ }^{\circ}$ del Decreto 2652 de 1991 y el artículo 15 transitorio del Código de Procedimiento Penal, crea los juzgados de ejecución de penas y medidas de seguridad y señala como sedes las ciudades en las que funcionan establecimientos penitenciarios destinados al cumplimiento de las respectivas sanciones: Bogotá, Cúcuta, Ibagué, Popayán, Tunja, Palmira, Calarcá y Acacías.

Pese a lo anterior, trascurren cinco meses a partir de la expedición del primer acuerdo hasta que, de nuevo, el 30 de noviembre de 1993, la Sala Administrativa del Consejo Superior de la Judicatura expidió el Acuerdo 95 y procedió a aplicar algunos ajustes frente a la competencia de los aludidos funcionarios, así: los JEPYMs deben vigilar que se cumpla la política penitenciaria del Estado, establecida en el artículo 12 del Código Penal ${ }^{9}$. Verificará, además, que el tiempo de trabajo ${ }^{10}$, de estudio o de enseńanza ${ }^{11}$

9 Artículo 12, Decreto 100 de 1980. Función de la pena y de las medidas de seguridad (Decreto derogado por la Ley 599 del 2000). La pena tiene función retributiva, preventiva, protectora y resocializadora. Las medidas de seguridad persiguen fines de curación, tutela y rehabilitación.

10 Con respecto a la redención de penas, la Corte Constitucional, en la Sentencia C-394 de 1995, expresó que "los artículos referentes a la redención de penas, son un efecto legitimante y resocializador del trabajo. Pero nada obsta para que este tenga un cauce y un ordenamiento, así como una evaluación. Lo anterior, precisamente para evitar la arbitrariedad; la evaluación es un mecanismo de seriedad en el cumplimiento del deber de vigilar si el trabajo es acorde con las metas previstas, y una herramienta eficaz para corregir los defectos que se presenten. No hay por qué mirar la evaluación con desconfianza, sino como un instrumento que permite reconocer también los méritos de quien ejerce una labor; es decir, se trata de una objetivación del esfuerzo subjetivo".

11 El artículo 82 de la Ley 65 de 1993 reglamenta la redención así: "El juez de ejecución de penas y medidas de seguridad concederá la redención de pena por trabajo a los condenados a pena privativa de libertad. A los detenidos y a los condenados se les abonará un día de reclusión por dos días de trabajo. Para estos efectos no se podrán computar más de ocho horas diarias de trabajo. El juez de ejecución de penas y medidas de seguridad constatará en cualquier momento, el trabajo, la educación y la enseñanza que se estén llevando a cabo en los centros de reclusión de su jurisdicción y lo pondrá en conocimiento del director respectivo". 
Luz Mireya Mendieta Pineda, Mayda Goyte Pierre, Islen Yahír Oviedo El juez de ejecución de penas y las medidas de seguridad en Colombia...

que se aduzca para obtener la redención de la pena se haya prestado en cumplimiento de los programas elaborados por el Inpec.

Así, con fundamento en las leyes 2700 de 1991 y 65 de 1993 y en la reglamentación expedida por el Consejo Superior de la Judicatura, el Tribunal Superior del Distrito Judicial de Tunja designa como primer juez de todo el país, para la ciudad de Tunja, a la Dra. Alda Nubia Soler Rubio, quien nombra la planta de personal especializado ${ }^{12}$. El juzgado abre sus puertas el 1. ${ }^{\circ}$ de febrero de 1994 y comienza su labor con la vigilancia de las sentencias de las personas privadas de la libertad, siempre y cuando el sentenciado estuviese recluido en la Penitenciaría Nacional de El Barne. Con la expedición del Acuerdo 61 del 2 de junio de 1994, entró a operar el segundo juzgado en Medellín, y así sucesivamente en las demás ciudades que se había dispuesto en forma permanente.

Estos despachos judiciales tienen desde su origen una elevada carga laboral. Obsérvese el caso de Tunja: en 1994, el juzgado primero de ejecución de penas y medidas de seguridad contaba con cinco funcionarios para conocer del trámite de la ejecución de la pena de los privados de la libertad en la penitenciaría de El Barne y Tunja, que después se fue ampliando a los otros centros penitenciarios del circuito judicial de Tunja. En 1997, se contaba ya con dos juzgados y, según la Corte Constitucional, en la penitenciaría nacional de El Barne estaban privados de la libertad 789 condenados y cada uno de los jueces tenía competencia sobre 394 procesos (véase la tabla 1). De este mismo modo, se refieren los casos de todos los JEPYMs en el país en cuanto a su carga laboral, pues les corresponde una carga anual de 39839 procesos (Corte Constitucional, T-153 1998).

Tabla 1. Promedio de procesos de los Jepyms, 1997

\begin{tabular}{|c|c|c|c|}
\hline Establecimiento & N. ${ }^{\circ}$ condenados & $\mathrm{N} .^{\circ}$ jueces & Promedio \\
\hline La Picota & 1138 & 8 & 142 \\
\hline Picaleña & 1040 & 3 & 347 \\
\hline San Isidro & 876 & 2 & 438 \\
\hline El Barne & 789 & 2 & 394 \\
\hline
\end{tabular}

12 Un asistente jurídico (abogado con experiencia mínima de dos años en la rama judicial), un asistente con título de psicólogo, un escribiente y un conductor. 


\begin{tabular}{|lccc|}
\hline Establecimiento & $\mathbf{N}^{\circ}{ }^{\circ}$ condenados & N. ${ }^{\circ}$ jueces & Promedio \\
\hline Cúcuta & 676 & 1 & 676 \\
\hline Acacías & 594 & 1 & 594 \\
\hline Palmira & 576 & 2 & 288 \\
Calarcá & 499 & 1 & 499 \\
\hline El Bosque & 427 & 0 & 0 \\
\hline Itagüí & 219 & 3 & 73 \\
\hline
\end{tabular}

Fuente: Corte Constitucional, Sentencia T-153 de 1998.

Esa carga laboral que se ha ido incrementando ha desatado consecuencias negativas. Si se retoma el caso de Tunja, en mayo del 2018 había allí seis JEPyMs, que entraron en paro "por las pésimas condiciones laborales", por falta de insumos y equipos para trabajar y porque laboraban hasta las 10 de la noche para alcanzar a cumplir con las 10600 solicitudes que tenían que tramitar 13 personas. Se han venido identificando, además, el incremento de enfermedades laborales que pueden percibirse en dos funcionarios con problemas respiratorios, otros con estrés laboral, síndrome del túnel carpiano y presencia de ácaros (RCN Radio, 16 de mayo de 2018).

Pese a lo anterior, el Jepyms está considerado en la Constitución Política y la ley como el garante de la condición de ser humano de las personas privadas de la libertad y, por ello, el funcionario que desempeñe ese cargo debe cumplir con unos requisitos mínimos para acreditar su idoneidad para el cargo (véase la tabla 2).

Tabla 2. Requisitos para optar al cargo de juez de ejecución de penas y medidas de seguridad

\section{Requisitos generales}

- Ser colombiano de nacimiento y ciudadano en ejercicio y estar en pleno goce de sus derechos civiles;

- no estar incurso en causal de inhabilidad o incompatibilidad;

- tener título de abogado expedido por universidad reconocida oficialmente o convalidado conforme a la ley;

- no haber llegado a la edad de retiro forzoso (65 años).

\section{Requisitos específicos}

- Acreditar experiencia profesional por un periodo no inferior a cuatro años.

Fuente: los artículos 127 y 128 de la Ley 270 de 1996 establecen los requisitos generales y específicos que debe tener la persona aspirante a desempeñar el cargo de JEPYMs. 
Luz Mireya Mendieta Pineda, Mayda Goyte Pierre, Islen Yahír Oviedo

\section{DEBERES DE LOS JUECES DE EJECUCIÓN DE PENAS Y MEDIDAS DE SEGURIDAD}

La Corte Constitucional, fijó su posición con respecto a los deberes de los jueces de EPYMS, así:

La justicia de ejecución de penas y medidas de seguridad tiene la labor de vigilar que la pena cumpla su función resocializadora, así como los derechos y garantías a que tienen derecho los condenados y, en especial, las redenciones de pena por trabajo, estudio y enseńanza, y los consecuentes permisos a los que virtualmente son acreedores, sean una realidad efectiva. En razón de esta noble misión, estos jueces están en la obligación de suministrar a quienes se encuentran purgando una determinada pena, toda la información que se relacione con esta y que pueda tender a su redención o su disminución. (Corte constitucional, T 470, 1996)

De la información con que cuentan los mencionados funcionarios judiciales depende en gran medida la libertad personal de quien haya sido condenado por la comisión de un delito. Cuando se está privado de la libertad, la información que se relaciona con esta situación se convierte en un bien de carácter vital del que puede llegar a depender un número mucho mayor de derechos fundamentales, a diferencia de los que afectan a las personas que no se encuentran recluidas en centros carcelarios. Así, estos jueces tienen el deber de informarles, de oficio, todo traslado de los expedientes en que consten los respectivos procesos penales, así como toda decisión que incida en su situación de privación de la libertad (Corte constitucional, 1996).

\section{FUNCIÓN Y COMPETENCIA DE LOS JUECES DE EJECUCIÓN DE PENAS Y MEDIDAS DE SEGURIDAD}

La Corte Constitucional ha referido sobre el JepyMs que es "un funcionario especial encargado de verificar el cumplimiento de las sentencias impuestas por los operadores jurídicos penales, debido a que, como lo ha expuesto esta Corporación, la ejecución de una pena, en especial la privativa de la libertad, implica la restricción de algunos derechos fundamentales, con base en la necesidad de proteger ciertos bienes jurídicos y valores constitucionales" (Corte Constitucional, Sentencia 649 del 2016). 
Según la posición de Rafael Márquez Piñero (1993, p. 320 y 321) —que compartimos-, la función de los jueces de ejecución de penas es de tres clases:

(1) Función inspectora: referida a la vigilancia de la ejecución de la pena mediante visitas a los centros carcelarios y penitenciarios para establecer el cumplimiento de las normas. En el caso de Colombia, se trata de las leyes 65 de 1993, 1709 de 2014 y los reglamentos internos de los establecimientos; además, de los requerimientos realizados en sentencias de revisión de la Corte Constitucional (Sentencia T-388 del 2013).

(2) Función consultiva: se concreta en el dictamen que el juez debe emitir, como es el caso de los beneficios administrativos. Así lo aclara la Corte constitucional cuando afirma: "El competente para determinar si el beneficio administrativo concedido, se ajusta o no a la legalidad, es el juez de ejecución de penas y medidas de seguridad" (Corte constitucional, Sentencia T-1093 del 2005) ${ }^{13}$.

(3) Función deliberativa o decisoria: está encaminada a resolver reclamaciones del condenado, como son los casos de libertades por pena cumplida, libertad condicional y redenciones de pena por trabajo, estudio o enseñanza.

La Corte Constitucional, con respecto a las funciones de este tipo de funcionario, indica que "sus funciones [están] orientadas a garantizar la legalidad de la sanción, a supervisar y controlar la ejecución de la pena" (Sentencia T-753 de 2005), lo que se lleva a cabo "verificando el cumplimiento efectivo de estas condiciones establecidas legalmente, para determinar si la persona a favor de quien se solicitan los beneficios es acreedora de los mismos" (Sentencia C-312 de 2002).

En cumplimiento de esta última función, los artículos 38 de la Ley 906 del 2004 y 51 de la Ley 65 de 1993 reglamentan la competencia de los jueces de ejecución de penas y medidas de seguridad, según estos factores:

13 Véanse los artículos 146, 147, 147a , 147b, 148 y 149 de la Ley 65 de 1993. En estas disposiciones se consagra la facultad de otorgar los diferentes beneficios administrativos en cabeza de la dirección del respectivo instituto penitenciario y carcelario. 
(1) Decisiones necesarias para que las sentencias ejecutoriadas que impongan sanciones penales se cumplan.

(2) Acumulación jurídica de penas.

(3) Libertad condicional y su revocatoria.

(4) Todo relacionado con la redención de pena por trabajo, estudio o enseñanza.

(5) Reconocimiento de beneficios administrativos que supongan una modificación en las condiciones de cumplimiento de la condena o una reducción del tiempo de privación efectiva de libertad.

(6) Verificación del lugar y condiciones en que se deba cumplir la pena o la medida de seguridad. Asimismo, del control para exigir los correctivos o imponerlos si se desatienden, y la forma como se cumplen las medidas de seguridad impuestas a los inimputables.

(7) Aplicación del principio de favorabilidad

(8) Extinción de la sanción penal.

(9) Reconocimiento de la ineficacia de la sentencia condenatoria.

(10) Garantía de la legalidad de la ejecución de las sanciones penales.

(11) Seguimiento de las actividades dirigidas a la integración social del interno.

(12) Conocimiento de las peticiones que los internos formulen en relación con el reglamento interno y el tratamiento penitenciario, en lo referente a los derechos y beneficios que afecten la ejecución de la pena.

La Corte, al referirse al JEPYMs con respecto a su competencia, afirmó:

En el ordenamiento penal colombiano, el juez de Ejecución de Penas y Medidas de Seguridad, es un funcionario especial encargado de verificar el cumplimiento de las sentencias impuestas por los operadores jurídicos penales, 
debido a que la ejecución de una pena, en especial la privativa de la libertad, implica la restricción de algunos derechos fundamentales, con base en la necesidad de proteger ciertos bienes jurídicos y valores constitucionales. Al Estado le compete garantizar de una parte, el cumplimiento de la condena y de otra, la efectividad de los principios de necesidad, utilidad y proporcionalidad durante el periodo de ejecución de la sanción punitiva. (Corte Constitucional, T-649 del 2016)

En México se establece que dentro de las funciones del juez de ejecución está "la aplicación de penas alternativas a la prisión, la concesión de beneficios o el lugar donde se deba extinguir la pena" (Olvera López, 2011, p. 241). En Brasil, el juez de ejecución penal y el Consejo Penitenciario son las dos instancias fundamentales en lo relativo a la ejecución de las penas, y el Juez es quien ha oído del Ministerio Público, acuerda la concesión de la libertad condicional (Alonso de Escamilla, 1985). Adam y Olivieri (2009), por su parte, en un estudio de las funciones de los jueces de ejecución refieren que una de las garantías más descuidadas es que el juez delega la ejecución del encierro y la determinación de las condiciones a la administración penitenciaria.

Guzman y Rambao (2019) analizan el rol de los jueces de ejecución de penas y medidas de seguridad en el modo como ejercen el seguimiento al cumplimiento de la reinserción social del condenado, dentro del proyecto Reinserción Social en el Caribe Colombiano. Igualmente, Ruiz Hernández (2011) formula críticas a la forma como funciona el sistema de ejecución de penas y medidas de seguridad en Colombia porque considera que en él se dan contradicciones entre normas de diversas jerarquías.

\section{FASE DE EJECUCIÓN DE LA SANCIÓN PENAL}

La ejecución de la pena se considera la última fase del proceso penal, que inicia cuando la sentencia condenatoria queda en firme y se ha proferido un fallo de carácter condenatorio que conduce a la imposición de la pena de prisión. Su finalidad es que un juez diferente al que conoció del proceso en la etapa de juzgamiento y de condena 
Luz Mireya Mendieta Pineda, Mayda Goyte Pierre, Islen Yahír Oviedo

El juez de ejecución de penas y las medidas de seguridad en Colombia...

sea el llamado a vigilar su ejecución y cumplimiento, pues es esa la etapa en la que se busca la resocialización ${ }^{14}$ de la persona.

Efectivamente, a través de un trabajo en equipo entre la rama judicial y la rama ejecutiva (Inpec), se pretende alcanzar la meta propuesta en la Ley 65 de 1993, esto es, la readaptación del individuo a la sociedad, como un ser útil a esta. No obstante, ya es bien sabido que esto no es así y que, en la realidad, cada organismo trabaja independientemente, con escasez de personal, poco presupuesto y con altos volúmenes de trabajo. Esta situación ha llevado a alertar a organismos internacionales y nacionales sobe la problemática carcelaria e, incluso, llevó a la Corte Constitucional a declarar el estado de cosas inconstitucional mediante la Sentencia T-153 de 1998 ${ }^{15}$, la Sentencia T-388 del $2013^{16}$ y la T-762 del $2015^{17}$.

Esta fase, como lo ha mencionado la Corte, es de trabajo en equipo entre el poder ejecutivo y el judicial, "requiere el ejercicio concurrente de una actividad coercitiva y administrativa de los centros de reclusión, asignada al ejecutivo, y de una función

14 En la realidad, esto es imposible de cumplir, como lo ha señalado la Corte Constitucional: "Ese nivel de hacinamiento ha generado que en los establecimientos de reclusión se vulneren de manera sistemática los derechos de las personas privadas de la libertad, pues impide que estas tengan lugares dignos donde dormir, comer, realizar sus necesidades fisiológicas, tener visitas conyugales e íntimas, ejercer actividades de recreación, de formación y de resocialización, entre otros” (Corte Constitucional, Sentencia T-762 del 2005).

15 "Esta Corporación ha hecho uso de la figura del estado de cosas inconstitucional con el fin de buscar remedio a situaciones de vulneración de los derechos fundamentales que tengan un carácter general —en tanto que afectan a multitud de personas — y cuyas causas sean de naturaleza estructural —es decir que, por lo regular, no se originan de manera exclusiva en la autoridad demandada y, por lo tanto, su solución exige la acción mancomunada de distintas entidades - En estas condiciones, la Corte ha considerado que dado que miles de personas se encuentran en igual situación y que si todas acudieran a la tutela podrían congestionar de manera innecesaria la administración de justicia, lo más indicado es dictar órdenes a las instituciones oficiales competentes con el fin de que pongan en acción sus facultades para eliminar ese estado de cosas inconstitucional".

16 "El Sistema penitenciario y carcelario colombiano afronta una emergencia, debido a los problemas que actualmente afronta, como la sobrepoblación, la precariedad de la infraestructura y la existencia de graves condiciones sanitarias e higiénicas que tienen en riesgo la salud pública de la población carcelaria e impiden la convivencia dentro de los centros carcelarios".

17 "Se traduce en situaciones de ingobernabilidad y violencia que muchas veces atentan contra la vida y la integridad de los presos; propicia la propagación de enfermedades y epidemias que afectan la salubridad pública y la salud de los reclusos; y desdibuja cualquier pretensión resocializadora y de redención o sustitución de la pena que un condenado pueda tener". 
judicial, encaminada a garantizar la realización efectiva de los principios y fines de la pena, encargada a los jueces de ejecución de penas y medidas de seguridad"18.

Sin embargo, pese al trabajo que debe desempeñar el ejecutivo y el judicial no se cumple a cabalidad con la función de resocialización que se busca del privado de la libertad en la etapa de la ejecución de la pena, muchos de ellos vuelven a la reincidencia (véase la figura 1 ).

Figura 1. Población condenada frente a población reincidente, 2013-2017 ${ }^{19}$

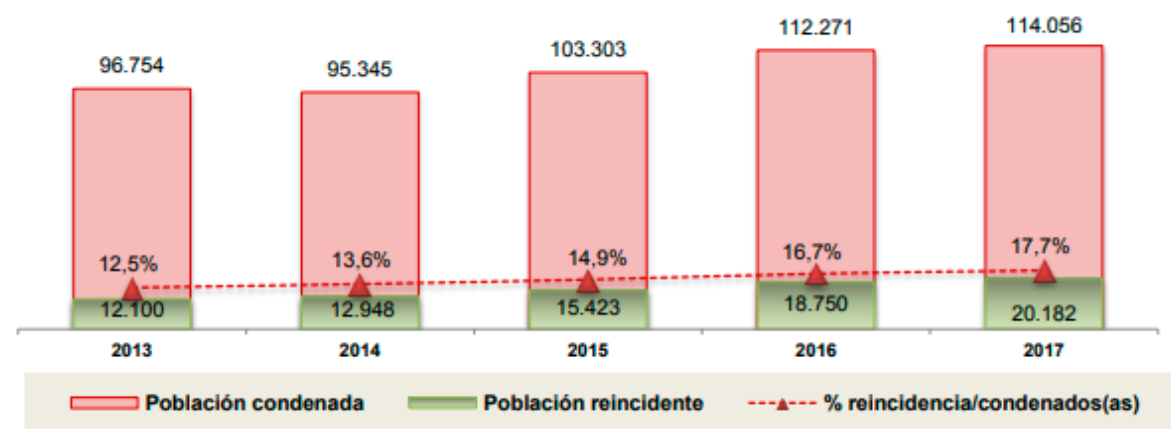

Fuente: Inpec (2017).

La anterior gráfica muestra la cifra de reincidencia desde el año 2013 al 2017 frente a la población condenada privada de la libertad que ha promediado entre 12100 a 20182 las personas que incursionan nuevamente en el delito, que en lugar de disminuir por el contrario año a año aumenta esta población.

18 Sentencia C-312 del 2001, M. P. Rodrigo Escobar Gil).

19 Revista Entre muros para la libertad (Inpec, 2017, p. 93). 
Luz Mireya Mendieta Pineda, Mayda Goyte Pierre, Islen Yahír Oviedo

\section{Posición de la Corte Suprema de Justicia SOBRE LA COMPETENCIA DEL JEPYMS}

La posición de la Sala de Casación Penal de la Corte Suprema de Justicia ha derivado de diferentes situaciones que se presentan alrededor del cumplimiento de la pena de prisión impuesta, a partir de los cual se han tomado las siguientes determinaciones:

- Condenado en libertad por el proceso 47959, pero privado de la misma por cuenta de otra actuación: "en aquellos casos en los cuales el penado se encuentra privado de la libertad, impera el factor personal, en tanto que la vigilancia de la sentencia estará asignada al despacho con sede en el lugar donde el condenado esté recluido. Si este último cambia, por ser trasladado el interno a otro sitio, también se desplazará la competencia de los jueces ejecutores" (Corte Suprema de Justicia, 2016b). Y en la misma aclaró: "En el evento en que el penado se encuentre en libertad, corresponde la vigilancia de la condena a los juzgados ejecutores que ejercen jurisdicción en la sede del fallador de conocimiento y en los eventos en los que no haya un funcionario de tal categoría y especialidad, opera la regla exceptiva, prevista en el inciso $3 .^{\circ}$ del artículo $10^{\circ}$ del Acuerdo 54 de 1994, en el sentido de que dicha función la ejercerá el respectivo juez de primera instancia que emitió la condena" (Corte Suprema de Justicia, 2016b).

- Con respecto a la sustitución de la ejecución de la pena conforme al artículo 461 de la Ley 906 del 2004, estableció que "en el sistema de enjuiciamiento penal con tendencia acusatoria no cabe pronunciamiento alguno de los jueces de instancia sobre la sustitución de la prisión intramural por la domiciliaria por cuanto, a voces del artículo 461 de la Ley 906 del 2004, esta es una competencia reservada al juez de ejecución de penas y medidas de seguridad. Únicamente, en la hipótesis de encontrar satisfechos los presupuestos normativos que regulan el instituto de la detención domiciliaria, al momento de proferir sentencia, habría lugar a conceder la sustitución de la medida, no así, la prisión domiciliaria" (Corte Suprema de Justicia, 2016a).

- Condenados pendientes de resolver recurso de reposición. "De conformidad con el artículo 38 de la Ley 906 del 2004, los jueces de ejecución de penas y medidas de seguridad tienen competencia para conocer de la ejecución y 
vigilancia de las penas y sanciones, correspondiendo la misma al juzgado del lugar en donde se encuentre privado de la libertad el condenado, como también de todas las circunstancias que de allí deriven, incluida desde luego la definición de los recursos de reposición que se interpongan contra las decisiones adoptadas" (Corte Suprema de Justicia, 2014b).

- Excepción de competencia: "Se exceptúan de dicha regla aquellos eventos en los cuales en el territorio de ubicación de la cárcel no exista Juez de Ejecución de Penas y Medidas de Seguridad, caso en el cual la competencia corresponde al Juez que haya proferido la sentencia de primera instancia" (Corte Suprema de Justicia, 2014a).

- Cuando el sentenciado disfruta de la libertad, la Corte ha dicho que "el funcionario competente para conocer de la ejecución de la sentencia lo será el juez de ejecución de penas y medidas de seguridad del lugar donde la misma se hubiese proferido. $Y$, de no despachar alli un juez de dicha categoría y especialidad, opera la regla exceptiva de que dicha función la ejerce el juez de instancia respectivo" ${ }^{\text {"20. }}$.

- Cambio de competencia: "cuantas veces haya lugar al cambio de sitio de reclusión, igual mudará la competencia. En otras palabras: el factor que debe dirimir el conflicto es personal, esto es, que sigue a la persona del sentenciado" (Corte Suprema de Justicia, 2016c).

\section{TENSIONES ENTRE LAS FUNCIONES Y EL TRABAJO DE LOS JUECES DE EJECUCIÓN DE PENAS Y MEDIDAS DE SEGURIDAD}

Desde su inicio 1994, los juzgados de ejecución de penas y medidas de seguridad empezaron con un gran cúmulo de trabajo frente a la población condenada y privada de la libertad. Posteriormente, se extendió a todo los condenados no privados de la libertad porque estaban gozando de algún subrogado penal. Pese a que año tras

20 Véanse las sentencias CSJ AP, 4 ago 2004, rad. 22.536, reiterado en CSJ AP, 21 nov 2012, rad. 40215 y CSJ AP, 13 septiembre 2014, rad. 44303 . 
Luz Mireya Mendieta Pineda, Mayda Goyte Pierre, Islen Yahír Oviedo El juez de ejecución de penas y las medidas de seguridad en Colombia...

año se han creado más juzgados permanentes como también de descongestión, aún no se ha podido lograr un equilibrio que pueda garantizar a la población reclusa sus derechos fundamentales.

Por información reportada por el Consejo Superior de la Judicatura, se sabe que en el país existen 155 juzgados de ejecución de penas y medidas de seguridad que deben atender desde el 2013 hasta el 2018 una población reclusa de entre 82980 y 78464 condenados (Consejo Superior de la Judicatura. Sala Administrativa, s. f.). Las estadísticas del Inpec del 2018 reflejan esa realidad (véase la figura 2), que la convierte en un aspecto negativo para el preso que pretenda alcanzar su resocialización. A ello se suma la tasa de hacinamiento que se viene registrando desde 1998, cuando la Corte Constitucional declaró por primera vez el estado de cosas inconstitucional en los centros penitenciarios y carcelarios del país. Pese a las medidas ordenadas, aún hoy se continua con la misma problemática, no obstante, las ordenes emitidas en la sentencia T-388 del 2013 y T-762 del 2015, que nuevamente declararon el estado de cosas inconstitucional de los centros carcelarios y penitenciarios del país.

Figura 2. Evolución de la población condenada entre el 2013 y el 2018

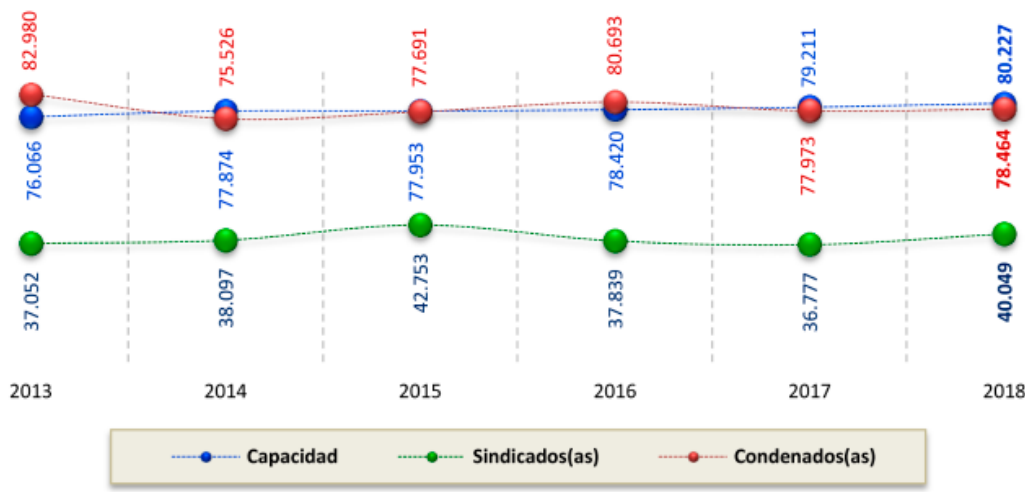

Fuente: Inpec (2018). Informe estadístico diciembre. Minjusticia, 12.

Estos son los datos en los años 2013: 82980; 2014: 75 526; 2015: 77 691; 2016: 80 693; 2017: 79211 y 2018: 80 227; ello implica que, si en el último año existen 155 jueces, aproximadamente cada uno de ellos debe vigilar la ejecución de la pena 
de un promedio de 517 personas privadas de la libertad, sin tener en cuenta aquellos sentenciados que disfrutan de su libertad, pero continúa la vigilancia de la pena o de la medida de seguridad en su caso.

Como puede apreciarse, estos jueces encargados del cumplimiento y efectividad de lo ordenado en la sentencia condenatoria y de la vigilancia y cumplimiento de los derechos fundamentales del condenado han pasado a ser funcionarios de oficina, mas no veedores de los derechos fundamentales que se lesionan a diario en los centros penitenciarios y carcelarios, como lo ha señalado en diferentes fallos de tutela la Corte Constitucional (Guarín y Aldana, 2016).

$\mathrm{Al}$ respecto, es de apreciar también la gran critica que puede formularse a este contraste claro y notorio entre la formalidad de la ley procesal penal y la disyuntiva existente en el juez de ejecución de penas y medidas de seguridad cuando, entre otras cuestiones, se enfrenta a los tiempos razonables que demanda la legislación y el quehacer normal de sus funciones, frente al hecho de velar por los derechos fundamentales de las personas privadas de la libertad.

En este sentido, debe tomarse atenta nota de todo el conjunto de consecuencias que puede acarrear para el ámbito de lo jurídico penal este gran conflicto o tensión, que se presenta en clave de un trabajo que culmina siendo formalista más que como garante de los derechos y las prerrogativas humanas más importantes de la población reclusa. No obstante, no solo ello es de decantarse y apreciarse en el marco de las discusiones legislativas, sino que, además, debe precisarse que todo este problema de falta de verdadera observancia de la garantía constitucional de los derechos de esta población se ve reflejada, en consecuencia, en una natural y decidida incidencia en la efectividad de la política criminal estatal.

En este contexto, el texto del profesor Ómar Huertas (2019) tiene una vigencia mayúscula, en tanto, a partir de sus consideraciones acerca del carácter de la política criminal sistémica, orienta las criticas fundamentales que bien merece traerse a colación en el presente escrito. Su postura, por un lado, da cuenta de los problemas más serios a los que se enfrenta la política criminal cuando su enfoque es precario o no tiene en cuenta el conjunto de elementos que aquella de corte sistémico sí toma en consideración y, por otro lado, profundiza la mirada crítica sobre la concepción 
Luz Mireya Mendieta Pineda, Mayda Goyte Pierre, Islen Yahír Oviedo

tradicional de la política criminal como un asunto meramente de corte jurídicopenal y, en su mayoría, punitivo (Huertas, 2019).

En este ámbito, es preciso apuntar que la dinámica formalista de los juzgados de ejecución de penas y medidas de seguridad en Colombia pasa por un tapiz de control absolutamente legalista de aquello que es objeto de su control y vigilancia. Pero no ocurre, sin embargo, con el asunto de fondo en clave de la política criminal: una posibilidad real y material de control de constitucionalidad y legalidad de la ejecución de la pena, en la búsqueda clara y directa de una auténtica resocialización y puesta en marcha de los verdaderos y originarios fines de la pena.

Con ello, naturalmente, y ante tal incumplimiento de la vigencia real de las garantías fundamentales de la población reclusa, se están desnaturalizando no solo los fines de la pena, en estricto sentido, sino que se desvirtúa cualquier intento de la política criminal frente a la resocialización del individuo. Esto, toda vez que la población pospenada amerita un especial tratamiento de resocialización que, a la postre, no solo consiste en la "enmienda" de su error trasgresor de la norma y violatorio de un bien jurídico, sino en su plena consciencia de no repetir tal conducta. Esta última cuestión le permite y lo habilita para volver a integrarse dentro del marco de legalidad a la vida en sociedad, en el marco de una convivencia pacífica y con sujeción a la normatividad vigente (Blanco y Gómez, 2016).

Otra de las tensiones evidentes que surgen de los análisis aquí planteados tiene que ver, ineludiblemente, con la extrema normativización de la vida social, pero, más aún, con la exigencia del cumplimiento de la legalidad en sentido estricto en el contexto de una sociedad del posconflicto. Huelga preguntarse, de la mano de Huertas (2018), si el principio de legalidad penal desempeña un papel determinante o no - y, de ser así, en qué forma lo hace — en el marco de la justicia transicional. El autor elabora al respecto toda una disertación no solo sobre este punto, sino, en más detalle, sobre el asunto de la legalidad estricta o la legalidad flexible (Molina, 2016; Humbarita, 2015).

Más allá de ahondar en el ya comentado tema — cuestión que desbordaría los límites temáticos propuestos en este escrito-, se encuentra el tema fundamental de una posible visión más garantista y de exigencia de legalidad flexible en la fase que compete 
al juez de ejecución de penas y de medidas de seguridad. Esto es, en otras palabras, la extrema necesidad que se tiene de no descontextualizar la justicia ordinaria, con sus notorias y clásicas exigencias formales frente a la legalidad, de la justicia transicional que, si bien no puede aplicarse para todos los delitos cometidos por todo el conjunto de la población colombiana, dada su naturaleza, sí debe servir como faro iluminador para guiar la labor fundamental de un juez, como los que se han venido estudiando a lo largo de este artículo. Es decir, la innegable e irrenunciable labor de velar por la garantía y vigencia de los derechos fundamentales de la población reclusa, en clave de la fase ejecutoria de su pena, en conexidad sistemática con la función de la pena relativa a la resocialización (Huertas, Leyva, Perdomo y Silvero, 2016).

En definitiva, de lo que se trata es de apreciar cómo ese papel que tanto se exige de la justicia transicional en Colombia - frente al asunto de la legalidad estricta o flexible, en palabras de Huertas (2018) - debe fungir como faro para orientar que, así como se busca una justicia, un carácter de reconciliación y una profunda reinserción detrás de todos los asuntos vinculados con las dinámicas de la sociedad del posconflicto, se surta del mismo modo una verdadera reivindicación del papel garantista de los jueces de ejecución de penas y medidas de seguridad, frente a la resocialización de los pospenados que esperan, tal como los excombatientes del conflicto, una segunda oportunidad por parte de la sociedad (Saidiza y Carvajal, 2016).

\section{CONCLUSIONES}

A lo largo del artículo se ha pretendido brindar una visión dl papel del juez de ejecución de penas y medidas de seguridad como protagonista en la fase de ejecución de la pena, como un símbolo de protección, preservación y salvaguarda de los derechos fundamentales del sentenciado. Es el encargado, además, del control y cumplimiento de la ejecución de la pena.

Del análisis documental recogido se concluye que esta figura nace con grandes expectativas al ser totalmente independiente de la administración penitenciaria (Inpec). Sin embargo, en los en más de 25 años que lleva en funcionamiento esa figura en Colombia, continúa la misma problemática de que no se alcanza la resocialización del penado, lo que se origina en varias circunstancias, como la violación de derechos 
Luz Mireya Mendieta Pineda, Mayda Goyte Pierre, Islen Yahír Oviedo

humanos, el hacinamiento carcelario y la carencia de recursos humanos y financieros que no le permiten al Jepyms garantizar, por lo menos, el principio de dignidad del privado de la libertad. Así lo ha mencionado en varios de sus fallos la Corte Constitucional.

Pese a que, entre otros factores, el artículo 7 de la Ley 1709 del 2014 pretendió producir cambios importantes con la reforma de la Ley 65 de 1993, como el de garantizar la presencia permanente de al menos un JEPYMs en establecimientos carcelarios que lo requieran, ello no ha podido convertirse en una realidad. Como agravante, el mismo artículo establece que estos funcionarios tienen "el deber de vigilar ${ }^{21}$ las condiciones" de la ejecución de la pena, lo que resulta imposible debido a las altas cargas de trabajo que estas personas mantienen. Eso les impide asistir a los centros de reclusión y resolver a tiempo las diferentes solicitudes que a diario les llegan, luego se ha convertido en jueces de cumplimiento de funciones en su despacho y han trasladado al Inpec la función de vigilar. De ahí que se pueda concluir, con el análisis de los diferentes fallos de tutela proferidos por la Corte Constitucional, que una de sus funciones más importantes, como es la función inspectora que tiene como juez constitucional en la fase de ejecución de la pena, es, en la realidad, letra muerta.

Es importante resaltar y reivindicar el papel de los jueces de ejecución de penas y medidas de seguridad en Colombia con relación a la vigencia y la garantía de los derechos fundamentales de la población reclusa, en clave de su aporte definitivo a la consecución del fin resocializador de la pena. Esto, de ninguna manera, puede llevarse a feliz término si la pena, en su ejecución, no respeta los estándares mínimos de observancia de los derechos constitucionales y legales en cabeza de los pospenados.

\section{REFERENCIAS}

Adam, Néstor N. H. y Olivieri, Cecilia C. B., (2009). El nuevo rol judicial en la ejecución de la pena. Recuperado de http://www.biblioteca.unlpam.edu.ar/rdata/tesis/e_adaeln762.pdf

21 Velar sobre una cosa, cuidar muy bien de ella. (Larousse, 1993, p. 1064) 
Alonso de Escamilla Avelina, A. (junio de 1985). La institución del juez de vigilancia en el derecho comparado: sus relaciones con la administraci6n administración penitenciaria. Comunicación presentada a las III Jornadas Penitenciarias Andaluzas. Granada, junio de junio 1985.

Blanco, C. y Gómez, D. (2016). Constitución política e integración andina desde las nociones de soberanía y democracia. En Perspectivas criticas del derecho constitucional colombiano. Bogotá, Colombia: Universidad Libre.

Corte Suprema de Justicia (2014). Proceso 43821. Número de providencia AP2992-2014. Magistrado ponente Luis Guillermo Salazar Otero

Corte Suprema de Justicia (2014). Proceso 44820. Número de providencia AP6252-2014. Magistrado ponente Eugenio Fernández Carlier

Corte Suprema de Justicia. (2016). Proceso 45905. Número de providencia SP914-2016. Magistrado ponente. Fernando Alberto Castro Caballero

Congreso de la República de Colombia. (1991). Ley 2700 de 1991, Código de Procedimiento Penal.

Congreso de la República de Colombia. (1993). Ley 65 de 1993, Código Penitenciario y Carcelario.

Congreso de la República de Colombia. (1996). Ley 270 de 1996, Estatutaria de Administración de Justicia.

Congreso de la República de Colombia. (2000). Ley 599 de 2000. Código Penal Colombiano.

Congreso de la República de Colombia. (2004). Ley 906 de 2004. Código de Procedimiento Penal.

Congreso de la República de Colombia. (2014). Ley 1709 de 2014. Reforma a la Ley 65 de 1993.

Consejo Superior de la Judicatura. (1993). Acuerdo 14 del 7 de junio de 1993, creación de los juzgados de ejecución de penas.

Consejo Superior de la Judicatura. (1993). Acuerdo 95 del 30 de noviembre de 1993, ajuste de competencia de los jueces.

Consejo Superior de la Judicatura. (1994). Acuerdo 54 del 24 de mayo de 1994, ajuste de competencia de los jueces de ejecución. 
Luz Mireya Mendieta Pineda, Mayda Goyte Pierre, Islen Yahír Oviedo El juez de ejecución de penas y las medidas de seguridad en Colombia...

Consejo Superior de la Judicatura. (1994). Acuerdo 061 de 2 de junio de 1994, creación del Juzgado de Ejecución de Penas de Medellín.

Consejo Superior de la Judicatura. (1999). Acuerdo 548 de 1999, creación del Circuito Penitenciario y Carcelario de Tunja.

Consejo Superior de la Judicatura. Sala Administrativa. Unidad de Desarrollo y Análisis Estadístico. Cuantificación de despachos judiciales. Recuperado de https://ramajudicial.gov.co/ web/unidad-de-desarrollo-y-analisis-estadistico1/cuantificacion-de-despachos-judiciales

Corte Constitucional. (1995). Sentencia T 065 de 1995. Magistrado Ponente [M. P. Alejandro Martínez Caballero.].

Corte Constitucional. (1996). Sentencia T 470 de 1996. Magistrado Ponente [M. P. Eduardo Cifuentes Muńoz].

Corte Constitucional. (1998). Sentencia T 153 de 1998. Magistrado Ponente [M. P. Eduardo Cifuentes Muñoz].

Corte Constitucional. (2002). Sentencia C-312 del 2002. Magistrado Ponente [M. P. Rodrigo Escobar Gil].

Corte Constitucional. (2005). Sentencia T-753 del 2005. Magistrado Ponente [M. P. Jaime Araujo Rentería].

Corte Constitucional. (2005). Sentencia T-762 del 2015. Magistrado Ponente [M. P. Gloria Stella Ortiz Delgado].

Corte Constitucional. (2005). Sentencia T-1093 del 2005. Magistrado Ponente [M. P. Clara Inés Vargas Hernández].

Corte Constitucional. (2013). Sentencia T-388 del 2013. Magistrado Ponente [M. P. María Victoria Calle Correa].

Corte Constitucional. (2016). Sentencia T- 649 del 2016. Magistrado Ponente [M. P. Gloria Stella Ortiz Delgado].

Corte Suprema de Justicia. (2014a). Proceso 43821. Número de providencia AP2992-2014. [M. P. Luis Guillermo Salazar Otero].

Corte Suprema de Justicia. (2014b). Proceso 44820. Número de providencia AP6252-2014.

[M. P. Eugenio Fernández Carlier]. 
Corte Suprema de Justicia. (2016a). Proceso 45905. Número de providencia SP914-2016. [M. P. Fernando Alberto Castro Caballero].

Corte Suprema de Justicia. (2016b). Proceso 47959. Número de providencia AP2510-2016. Magistrado Ponente [M. P. Eugenio Fernández Carlier].

Corte Suprema de Justicia. (2016c). Proceso: 48206. Número de providencia AP4738-2016. Magistrado Ponente [M. P. José Francisco Acuña Vizcaya].

De Escamilla, A. (1986). La institución del juez de vigilancia en el derecho comparado: sus relaciones con la administración penitenciaria. Recuperado de http://dialnet.unirioja.es/ servlet/articulo? codigo $=46282$

Garzón, E. (2013). Globalización del derecho, fetichismo legal el velo de los derechos humanos. Revista Verba Iuris, 30, 45-69.

Gracia, L., Boldova, M. A. y Alastuey, M. C. (2012). Lecciones de consecuencias jurídicas del delito, (4. ${ }^{a}$ ed.). Valencia (España): Tirant lo Bllanch.

Guarín, E. A. y Aldana, J. (2016). Estado jurisdiccional y bien común. Revista Verba Iuris, 11(36), 13-26.

Guzmán González, P. y Rambao Hernández, J. (2019). La función de reinserción social y el papel de los jueces de ejecución de penas y medidas de seguridad en Colombia. Justicia, 24(35). Documento extraído el 3 de enero del 2018. Recuperado de https://doi. org/10.17081/just.24.35.3398

Huertas Díaz, O. (2018). Principio de legalidad penal y justicia transicional en Colombia. Legalidad estricta o legalidad flexible. Grupo Editorial Ibáñez. Bogotá: Grupo Editorial Ibáñez.

Huertas Díaz, O. (2019). Política criminal sistémica. Origen rizomático y contribuciones para su reflexión. Grupo Editorial Ibáńez. Bogotá: Grupo Editorial Ibáñez.

Huertas, O., Leyva, M., Lugo, L., Perdomo, W. y Silvero, A. (2016). Entre la minimización y la expansión del derecho penal: la presencia de Beccaria en el debate contemporáneo. Revista Iusta, 44(1).

Humbarita, J. (2015) Derecho constitucional hispanoamericano frente a la realidad institucional: manifiesta divergencia. Revista Iusta, N. ${ }^{\circ} 43$ (2) 
Luz Mireya Mendieta Pineda, Mayda Goyte Pierre, Islen Yahír Oviedo El juez de ejecución de penas y las medidas de seguridad en Colombia...

Instituto Nacional Penitenciario y Carcelario (Inpec) (2017). Revista entre muros para la libertad, 2017. 2(23).

Instituto Nacional Penitenciario y Carcelario (Inpec) (2018). Informe estadístico de diciembre. Minjusticia, 12 Recuperado de http:/www.inpec.gov.co/web/guest/ estadisticas/informes-y-boletines?p_p_id=com_liferay_document_library_web_ portlet_DLPortlet_INSTANCE_6SjHVBGriPOM\&p_p_lifecycle=0\&p_p_ state=normal\&p_p_mode=view\&_com_liferay_document_library_web_portlet_DLPortlet_INSTANCE_6SjHVBGriPOM_mvcRenderCommandName=\%2Fdocumen t_library\%2Fview

Larousse, (2002). Diccionario enciclopédico. Bogotá: Larousse.

Márquez, R. (1993). Comentarios a la Ley de Normas mínimas sobre readaptación social de sentenciados, modernización del derecho mexicano, reformas constitucionales y legales 1992. México: Unam, Instituto de Investigaciones Jurídicas. Recuperado de biblio.juridicas. unam.mx/libros/2/957/17.pdf

Molina González, Y. (2016). Derecho penal del enemigo y dignidad humana. Revista Verba Iuris, 11(36), 135-146.

Olvera López, J. J. (2011). El juez de ejecución en materia penal. Revista del instituto de la judicatura federal, 31, 225-249. Recuperado de https://www.ijf.cjf.gob.mx/Penal/ biblioteca/9juez-spa/el-juez-de-ejecucion-en-materia-penal.pdf, 225- 249

Posada, A., N. R., 2010. Derecho penal: parte general-fundamentos. Medellín: Editorial Universidad de Medellín.

RCN Radio (16 de mayo del 2018). Juzgados de descongestión de penas de Tunja entraron en paro. Recuperado de https://www.rcnradio.com/colombia/region-central/juzgados-dedescongestion-de-penas-de-tunja-entraron-en-paro 5-02-2019

Ruiz Hernández, A. (1.er semestre del 2011). Revista Derecho y Realidad Facultad de Derecho y Ciencias Sociales, UPTC, 17(1), 47-68.

Saidiza, H. y Carvajal, J. (2016). Crisis del Estado de derecho en Colombia: un análisis desde la perspectiva de la legislación penal. Revista Iusta, 44(1), 17-39.

Sánchez Montoya, M. M. (2018). Función constitucional del juez de ejecución de penas. Recuperado de https://repository.udem.edu.co/handle/11407/4608 
VIeI Revista Virtual

Via Inveniendi et Iudicandi

Subijana, I. J. (2005). El juez en la ejecución de las penas privativas de libertad. Revista Electrónica de Ciencia Penal y Criminología, 7(11), 1-120.

Tirado, M., Bedoya, J. y Blanco, A. (2016). Bioética y transhumanidad: hacia una aproximación al consumo de sustancias nootropicas en el campo académico. Bioética y Docencia, pp. 91-119. Recuperado de https://repository.usta.edu.co/handle/11634/1527

Wexler, D. D. y Calderón, J. J. (2003). El juez de vigilancia penitenciaria: un modelo para la creación de juzgados de reinserción en las jurisdicciones angloamericanas en aplicación de los principios del "derecho terapéutico". Revista Española de Investigación Criminológica, pp. 67-98



